Metal-Mediated Synthesis

\title{
Stereospecific Suzuki Coupling with Inversion of Stereoconfiguration
}<smiles>CC(C)(C)OB1OC(C)(C)C(C)(C)O1</smiles>

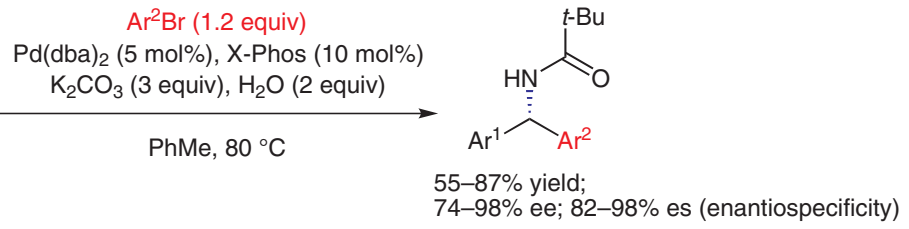<smiles>CC(=O)c1ccc(C(NC(=O)C(C)(C)C)c2ccccc2)cc1</smiles><smiles>CC(C)(C)C(=O)NC(c1ccccc1)c1ccc(C=O)cc1</smiles>
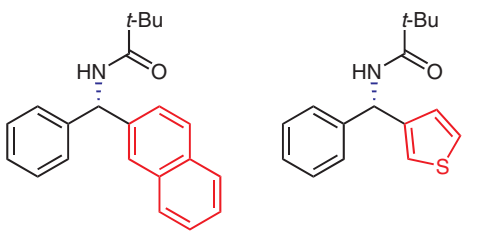

$76 \%$ yield; $92 \%$ ee; $96 \%$ es $\quad 80 \%$ yield; $92 \%$ ee; $96 \%$ es enantiopurity of starting enantiopurity of starting<smiles>CC(C)(C)C(=O)NC(c1ccccc1)c1cccnc1</smiles><smiles>COc1ccc(C(NC(=O)C(C)(C)C)c2ccccc2)cc1</smiles>

$83 \%$ yield; $88 \%$ ee; $92 \%$ es nantiopurity of starting

$79 \%$ yield; $98 \%$ ee; $98 \%$ es enantiopurity of starting

material: $96 \%$ ee

$$
\text { material: } 96 \% \text { ee }
$$
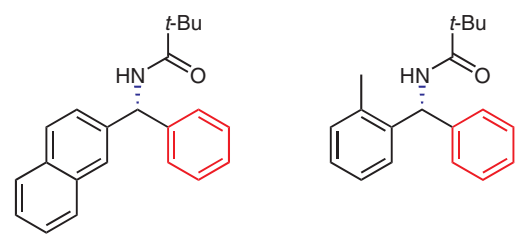

$68 \%$ yield; $95 \%$ ee; $95 \%$ es $\quad 55 \%$ yield; $74 \%$ ee; $82 \%$ es enantiopurity of starting enantiopurity of starting

Proposed mechanism:

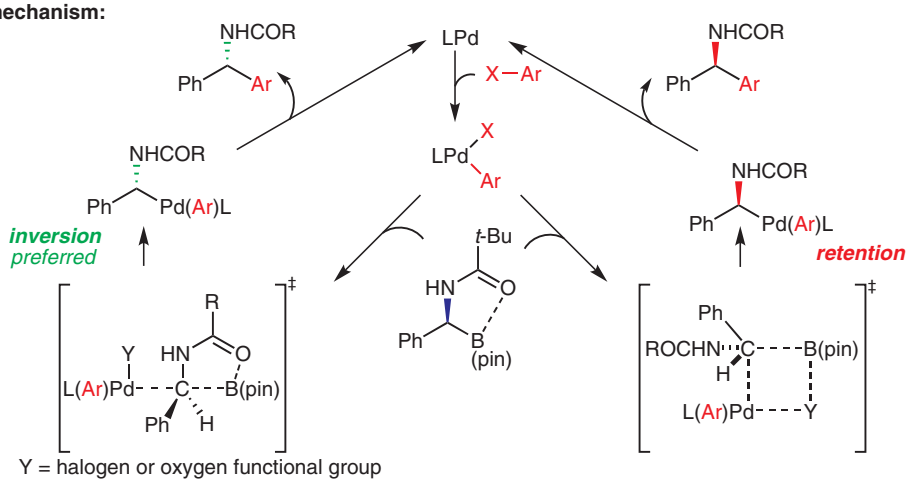

Significance: This article reports on the SuzukiMiyaura coupling of enantioenriched $\alpha$-(acylamino)benzylboronic acid that surprisingly proceeds with inversion of stereoconfiguration.
Comment: Strong intramolecular coordination of the carbonyl group to boron is considered responsible for the preferred backside attack of the palladium complex on the benzylic carbon atom.

SYNFACTS Contributors: Paul Knochel, Tobias Thaler 